\title{
Rock physics diagnostic of Eocene Sokor-1 reservoir in Termit subbasin, Niger
}

\author{
Amadou Hassane $^{1,2}$ (D) Chukwuemeka Ngozi Ehirim ${ }^{3} \cdot$ Tamunonengiyeofori Dagogo $^{3}$
}

Received: 31 March 2021 / Accepted: 9 August 2021 / Published online: 20 August 2021

(c) The Author(s) 2021

\begin{abstract}
Eocene Sokor-1 reservoir is intrinsically heterogeneous and characterized by low-contrast low-resistivity log responses in parts of the Termit subbasin. Discriminating lithology and fluid properties using petrophysics alone is complicated and undermines reservoir characterization. Petrophysics and rock physics were integrated through rock physics diagnostics (RPDs) modeling for detailed description of the reservoir microstructure and quality in the subbasin. Petrophysical evaluation shows that Sokor-1 sand_5 interval has good petrophysical properties across wells and prolific in hydrocarbons. RPD analysis revealed that this sand interval could be best described by the constant cement sand model in wells_2, $33, \ldots 5$ and _9 and friable sand model in well_4. The matrix structure varied mostly from clean and well-sorted unconsolidated sands as well as consolidated and cemented sandstones to deteriorating and poorly sorted shaly sands and shales/mudstones. The rock physics template built based on the constant cement sand model for representative well_2 diagnosed hydrocarbon bearing sands with low $V_{\mathrm{p}} / V_{\mathrm{s}}$ and medium-to-high impedance signatures. Brine shaly sands and shales/mudstones were diagnosed with moderate $V_{\mathrm{p}} / V_{\mathrm{s}}$ and medium-to-high impedance and high $V_{\mathrm{p}} / V_{\mathrm{s}}$ and medium impedance, respectively. These results reveal that hydrocarbon sands and brine shaly sands cannot be distinctively discriminated by the impedance property, since they exhibit similar impedance characteristics. However, hydrocarbon sands, brine shaly sands and shales/mudstones were completely discriminated by characteristic $V_{\mathrm{p}} / V_{\mathrm{s}}$ property. These results demonstrate the robust application of rock physics diagnostic modeling in quantitative reservoir characterization and may be quite useful in undrilled locations in the subbasin and fields with similar geologic settings.
\end{abstract}

Keywords Rock physics diagnostic $\cdot$ Rock physics template $\cdot$ Heuristic sand model $\cdot$ Reservoir microstructure

\section{Introduction}

Sedimentary rocks are considered as mechanical systems of mineral grains, pores and pore fluids formed by single or combinations of geologic processes. The environment of deposition and burial history controls textural and mineralogical characteristics of the rock and determines their geologic properties. The geologic properties, in turn, affect

Amadou Hassane

amabark@yahoo.com

1 The World Bank, ACE-CEFOR, University of Port Harcourt, Choba, Port Harcourt, Rivers State, Nigeria

2 Ministère du Pétrole, Immeuble Ex-ONAREM, BP 11700 Niamey, Niger

3 Geophysics Research Group, Physics Department, University of Port Harcourt, Box 122, Choba, Port Harcourt, Rivers State, Nigeria seismic elastic parameters through the rock and hence the observable acoustic response on records. Understanding the relationships between geologic properties and the seismic elastic parameters via rock physics is vital to the quantitative reservoir quality and hydrocarbon prospect evaluation from well and seismic data (Avseth et al. 2000; Ødegaard and Avseth 2004).

Rock physics is an indispensable tool for quantitative interpretation in reservoir studies, providing better understanding of the relationships between geologic properties and seismic elastic parameters. It represents the bridge that links geologic properties of porosity, clay content, saturation, lithology and texture and seismic elastic parameters such as $P$-wave velocity $\left(V_{\mathrm{p}}\right), S$-wave velocity $\left(V_{\mathrm{s}}\right)$ and their ratio $\left(V_{\mathrm{p}} / V_{\mathrm{s}}\right)$, acoustic impedance $(P$-Imp), bulk density and elastic moduli (Avseth et al. 2000, 2010; Simm and Bacon 2014). Through rock physics, texture and mineralogy of the reservoir rock can be evaluated and linked to the 
environment of deposition and diagenetic alterations (Avseth et al. 2010, 2014; Bjørlykke 2010).

Termit subbasin situated within the Chad Basin in Niger is filled with lower Cretaceous to Neogene sedimentary rocks (Fig. 1). The subbasin is hydrocarbon bearing with the major finds located in the upper Cretaceous to Paleocene-Eocene sandstones. Tectonic activities affected sedimentary processes such that structural, lithological and textural characteristics of the sediments are grossly impacted (Warren 2009). The reservoir sandstone intervals in some parts of the subbasin are radioactive with high clay content (Chang and Zung 2017), typical of low-contrast low-resistivity reservoirs (LCLRs) (Zhiqiang et al. 2007).

Discriminating reservoir sands from shales/mudstones and hydrocarbon sands from brine sands is complicated and tasking and undermines reservoir characterization in LCLRs using conventional petrophysical methods (Hassane et al. 2021). Therefore, the need for rock physics approach to evaluate reservoir microstructure and quality for enhanced reservoir characterization in the subbasin cannot be overemphasized.

Among the elastic parameters, elastic wave velocities (Pand S-wave velocities) of rocks exhibit heightened sensitivity to reservoir properties especially porosity. Wyllie et al. (1956) established a rock physics model showing a simple linear relationship between slowness (reciprocal of velocity) and porosity $(\phi)$ for water-saturated sandstones. Avseth et al. (2010, 2014), Bjørlykke (2010), Colin and Lennert (2011), Mahbaz et al. (2012) and Ahmad and Rowell (2013) showed how rock texture, environment of deposition and diagenesis could be evaluated from rock physics models of elastic moduli or velocities versus porosity crossplot planes. Generally, sediments exhibit distinct trends or clusters on the elastic moduli or velocities vs. porosity crossplots, due to textural and compositional differences (Dvorkin and Nur 1996; Dvorkin et al. 2002; Avseth et al. 2005). Therefore, rock physics models that relate elastic parameters to porosity and mineralogy form a critical part of rock physics diagnostic (RPD).

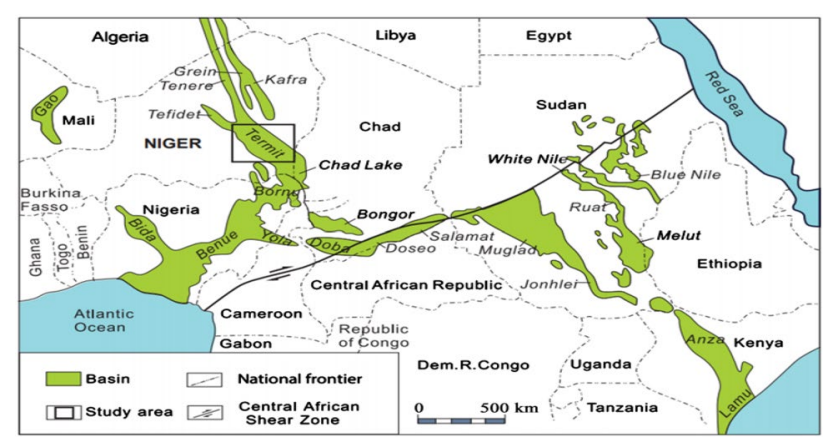

Fig. 1 Location map of the study area (Genik 1993)
RPD implies the use of rock physics models to predict rock texture from elastic properties vs. porosity crossplots (Avseth et al. 2005). A variety of models such as the theoretical, empirical, and heuristic can be used in rock physics analysis, each with its advantages and drawbacks (Mavko et al. 2009; Avseth et al. 2010). The heuristic model, which is a combination of theoretical and empirical rock physics models, provides better description of the reservoir microstructure and quality (Avseth et al. 2010). This includes the friable sand model (Dvorkin and Nur 1996), contact cement model (Dvorkin et al. 1994) and constant cement model (Avseth et al. 2005). These heuristic rock physics models provide a simple and practical way to model a wide range of elastic property-porosity trends describing depositional, sorting and cementation trends. This is done by fitting the observed data trends on elastic property versus porosity crossplot planes to appropriate rock physics models, to adequately characterize sediment texture (diagenetic cement, grain size, sorting, and clay content), evaluate reservoir quality and reservoir characterization (Avseth et. al. 2005).

The prediction of a rock physics model that explicitly describes the reservoir is of particular importance, and this can be used to build RPT of $V_{\mathrm{p}} / V_{\mathrm{s}}$ ratio versus acoustic impedance crossplot (Ødegaard and Avseth 2004), consistent with the local geology (Dvorkin and Nur 1996). RPT is a robust rock physics model built for a range of saturations and porosities for a given reservoir interval. It is useful for the prediction of the pore fluid and mineralogical content of a reservoir, reservoir characterization and prospect evaluation at well and away from well control points (Avseth et. al. 2005; Bosch et. al. 2017; Kabanda 2017).

The present study integrates petrophysics and rock physics modeling through rock physics diagnostics to characterize LCLR Eocene sandstone reservoir interval. This will significantly reduce exploration risk and improve reservoir mapping in Termit subbasin.

\section{Geology of the study area}

Termit subbasin consists of Donga, Yogou and Madama Formations in the upper Cretaceous, Sokor-1 in the Paleocene-Eocene and Sokor-2 in the Oligocene (Fig. 2). These formations were deposited in fluvial, lacustrine and marine environments during the various tectonics, with thickness ranging from about $3000 \mathrm{~m}$ to more than $12000 \mathrm{~m}$ (Genik 1992, 1993; Harouna and Philp 2012). The Donga Formation consists of marine sandstones at the base, mudstones, shales and siltstones in the middle and upper intervals.

The Yogou Formation consists mainly of mudstone and shale with disseminated sandstone intervals deposited in marine and transitional environments. The Upper Cretaceous marine mudstones of the Donga and Yogou

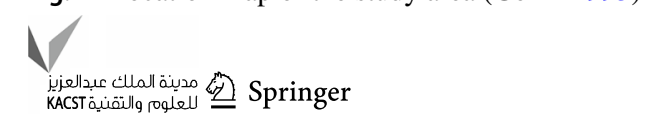


Fig. 2 Composite stratigraphic column of the Termit basin (Zhou et. al. 2017)

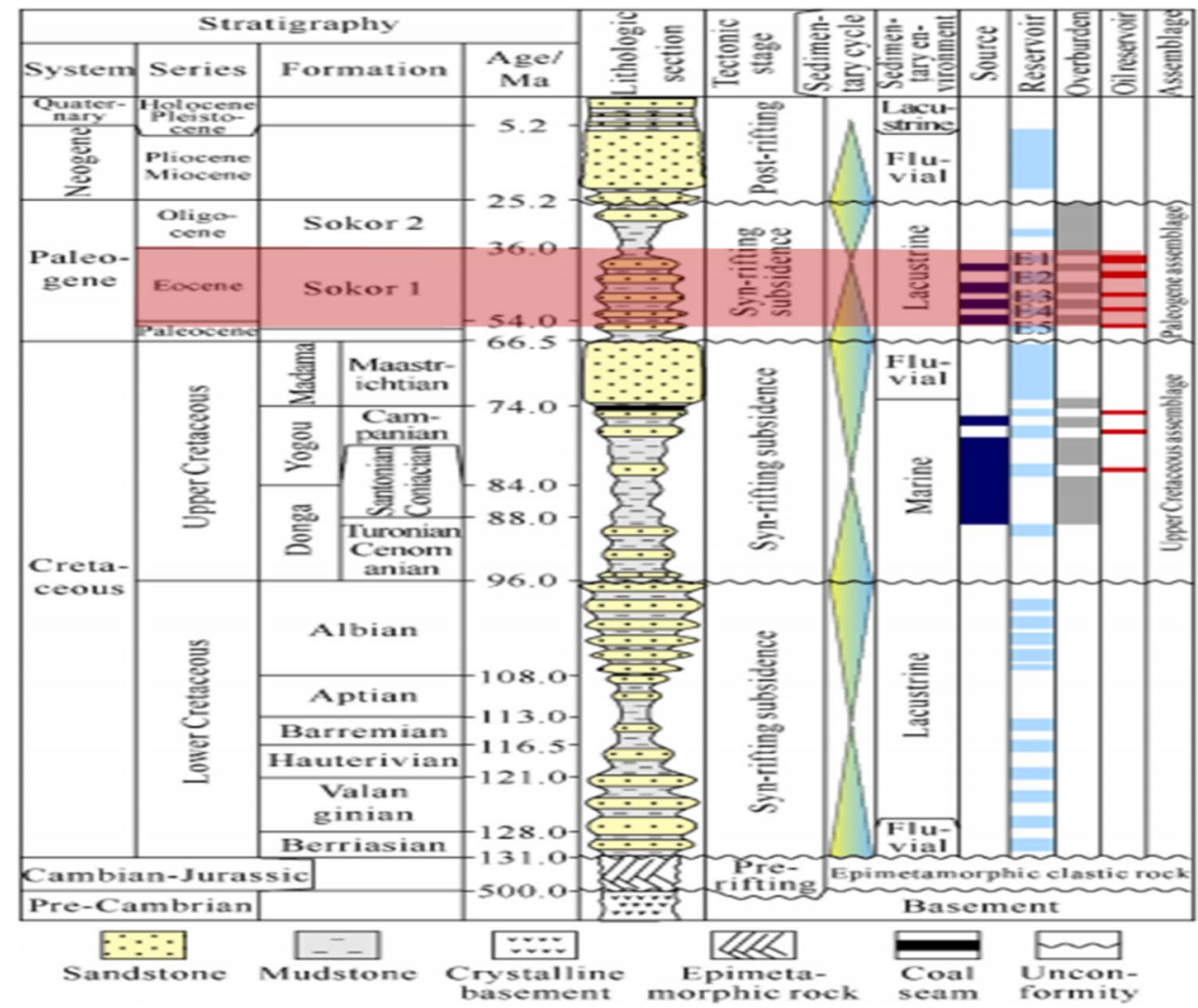

formations are the main source rock recognized in the basin (Zhou et al. 2017). The Madama Formation is characterized by massive fluvial sandstones interbedded with thin layers of muddy sandstones and coal seams (Liu et al. 2012, 2015; Wan et al. 2014). The Paleocene-Eocene Sokor-1 Formation consists of sandstones interbedded with shales/mudstones. Sokor-1 sandstones comprise six sand groups from top to bottom: $E 0, E 1, E 2, E 3, E 4$ and $E 5$, which are the main producing intervals in the subba$\sin$. The Sokor-2 Formation is mainly composed of lacustrine mudstones with the upper part consisting mainly of sandstone (Zhou et al. 2017; Wan et al. 2014). The overlying Neogene to Quaternary stratigraphic sequence consists of thick continental sediments, including alluvial, fluvial, deltaic and lacustrine sediments (Genik 1992, 1993).

Two petroleum systems Yogou-Sokor-1 and Sokor-1Sokor-2 were identified, with most of the hydrocarbon discoveries located in the upper Cretaceous Yogou and Sokor-1 Formations (Liu et al. 2015, 2019). The second member of the Sokor Formation (Sokor-2) acts as the regional seal in Sokor-1-Sokor-2 petroleum system, while the interbedded shale/mudstone in Sokor-1 and inter-channel mudstone in Yogou acts as local barrier/seal, respectively (Zhou et al. 2017).

These formations are penetrated and dissected by northwest-southeast (NW-SE) synthetic and north-northwest south-southeast (NNW-SSE) antithetic normal faults, respectively (Fig. 3), and northeast-southwest (NE-SW) transpressional anticlines (Lai et. al. 2020). The trap mechanism is mostly structural that favors hydrocarbon migration and accumulation with minor expressions of stratigraphic traps (Wan et al. 2014; Genik 1992).

\section{Method of study}

The principal data used for this study are well-log data from five wells (2, 3, 4, 5, and 9) spread across the field (Fig. 4). The well data are comprised of sonic (DT), gamma ray (GR), resistivity (LLD and LLS), neutron (NPHI/CNL) and density (RHOB) logs.

The study was carried in three main steps. The first step was the petrophysical analysis of the well logs. In this step, reservoir evaluation and analysis were carried out using gamma ray, resistivity and crossplots of shallow (LLS) vs. deep (LLD) resistivity and density vs. neutron logs to identify and map reservoirs and characterize pore fluids. The mapped reservoir interval was evaluated to estimate reservoir properties such as volume of shale $(V \mathrm{sh})$, porosity $(\phi)$ and water saturation and subsequently correlated across all the five wells in the field. Furthermore, pseudo-logs of shear wave velocity $\left(V_{\mathrm{s}}\right)$, bulk modulus,

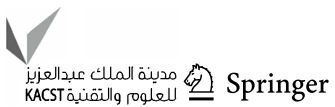




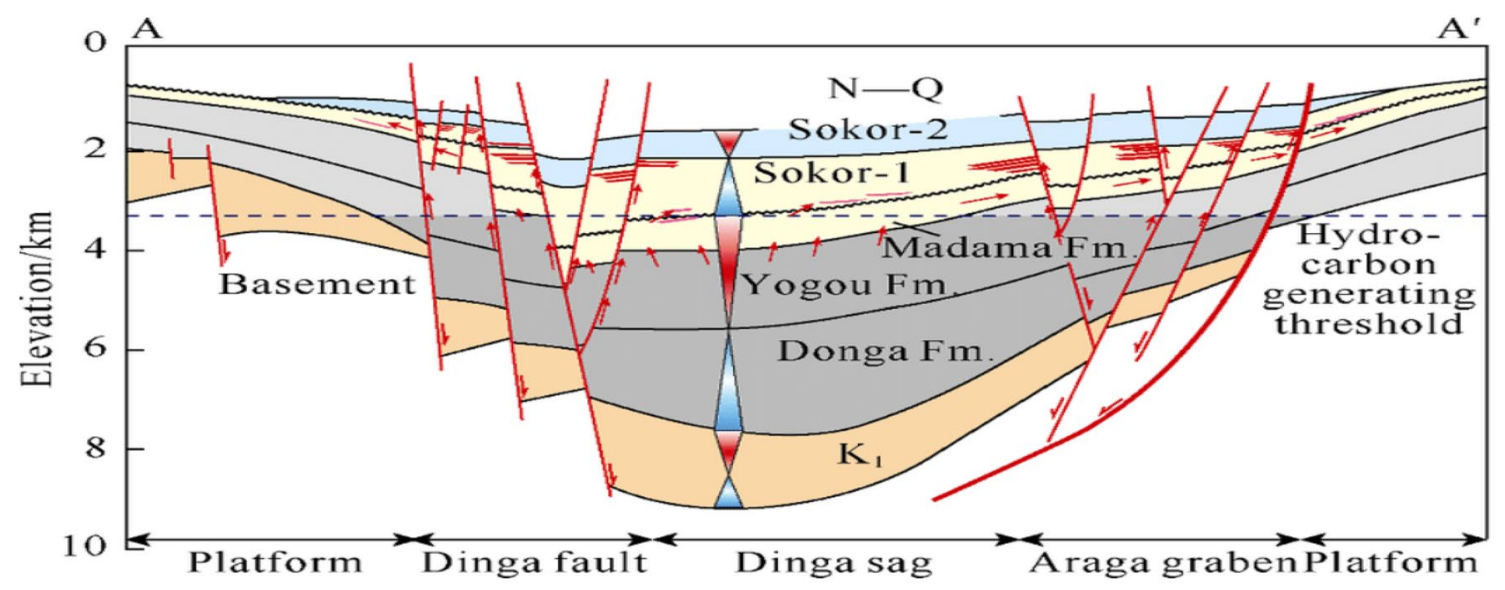

Fig. 3 Structural and stratigraphic framework of Termit basin (Genik 1993; Wan et al. 2014; Zhou et al. 2017)

Fig. 4 Base map of the study the study area showing the well locations

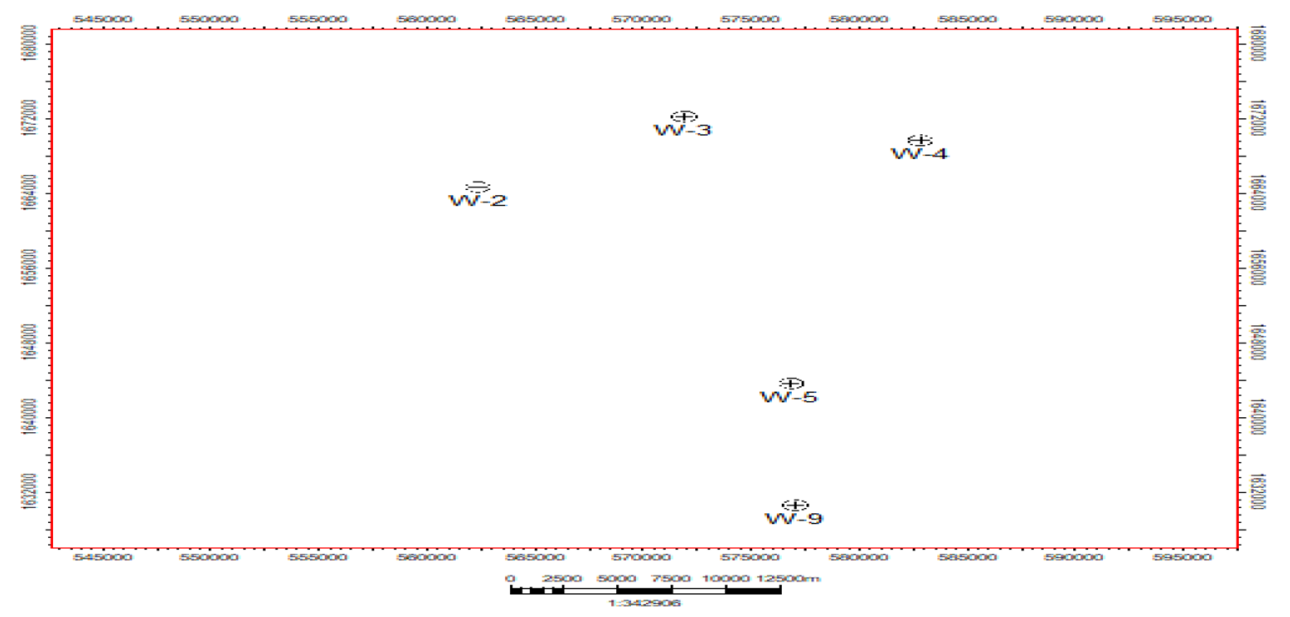

Finally, the fitting rock physics sand model was employed and constrained by the local geology, to generate a suitable RPT of $V_{\mathrm{p}} / V_{\mathrm{s}}$ versus acoustic impedance in the subbasin. Geologic constraints on rock physics model include lithology, mineralogy, burial depth, diagenesis (cementation), pressure and temperature.

\section{Results presentation}

Reservoir sand_5 was delineated and pore fluids were characterized by low-to-medium GR and low-resistivity log responses with fairly large density-neutron and LLS versus LLD crossover and separations, respectively, across the five wells. The mapped reservoir interval consists of fairly thick sandstone beds with intercalations of thin shales/mudstones within Sokor-1 Formation. Results of the petrophysical evaluation show that the reservoir interval has average reservoir properties of $61.4 \mathrm{~m}, 16.4 \%, 83.6 \%, 24.4 \%$ and $16.6 \%$ for thickness $(t)$, volume of shale $\left(V_{\mathrm{sh}}\right)$, net-to gross interval. 


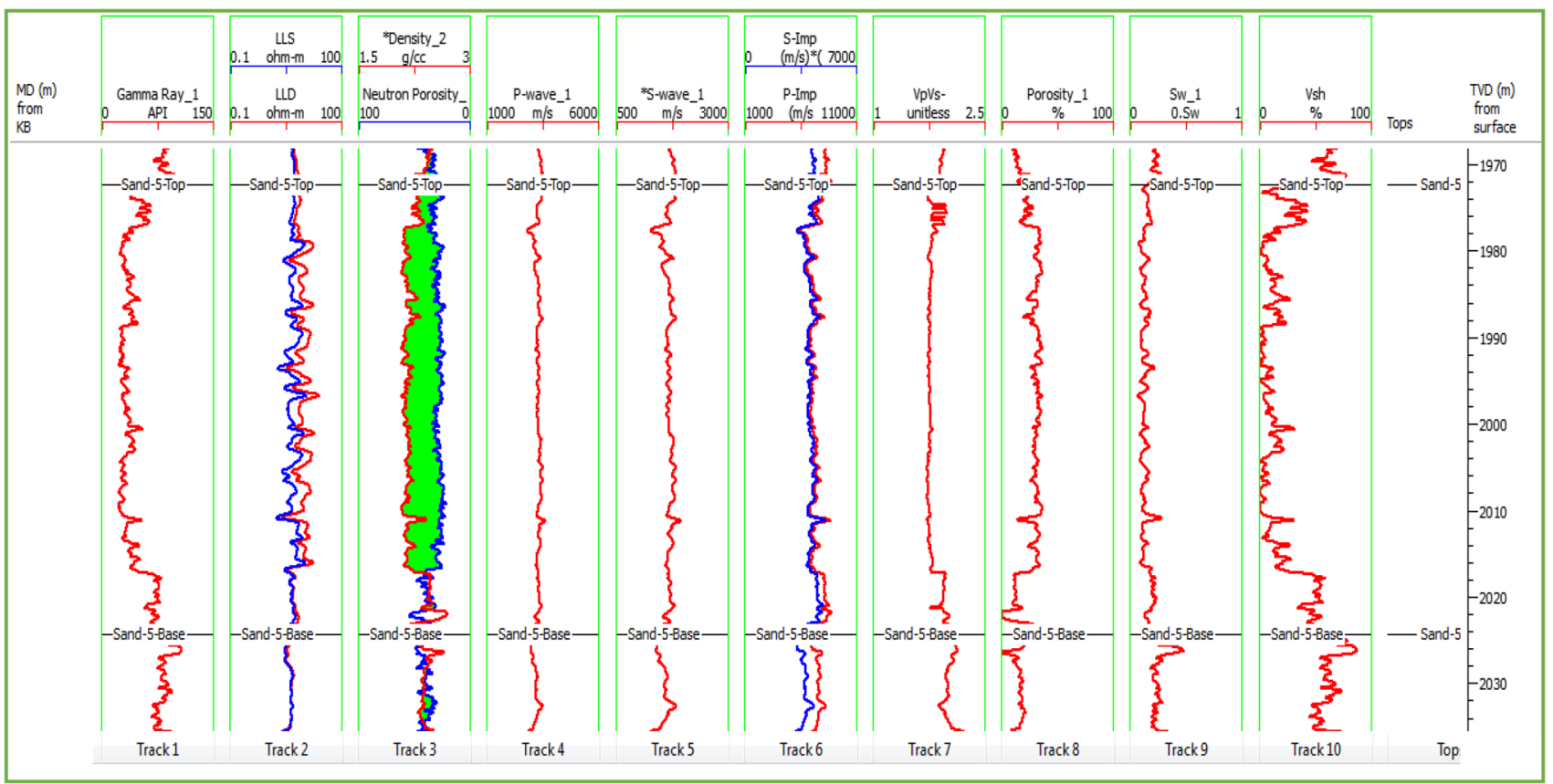

Fig. 5 Elastic and petrophysical logs for Well_2 Sand_ 5 reservoir interval

$(N / G)$, porosity $(\phi)$ and water saturation $\left(S_{\mathrm{w}}\right)$, respectively (Table 1).

These results suggest that sand_5 reservoir interval has good reservoir characteristics across wells and prolific in hydrocarbons (oil). The reservoir interval was correlated across wells and result shows continuous but varying reservoir thicknesses and depths from well to well, which could be related to the tectonics of the subbasin (Fig. 6). Of the five wells evaluated, well_2 sand_5 reservoir interval has the best reservoir properties and therefore has been chosen as the representative well for RPT analysis.

Rock physics diagnostic plot of $V_{\mathrm{p}}$ versus $\phi$ (Por) for sand_5 reservoir interval color coded with $V_{\text {sh }}$ produced distinct data trends in each well (Fig. 7). Wells_2 and_3 exhibit better data cluster and well-defined trends than wells_4, _5 and _9. The data trends generally fall fairly along the horizontal on the $V_{\mathrm{p}}-\phi$ plane, suggesting grain size distribution of different lithologies that vary between very clean and well-sorted sandstones to deteriorating and poorly sorted shaly sands and shales/mudstones. The sandstones and shales/mudstones are mostly dominated by quartz and clay mineral grains, respectively.

Reservoir velocities varied from 2700 to $3800 \mathrm{~m} / \mathrm{s}$ and porosities from zero end point (mineral point) to the second end point at high porosity $36 \%$. On the basis of the $V_{\mathrm{p}}$ versus $\phi$ crossplot, reservoir matrix mostly of clean sandstones (low $V_{\text {sh }}$ ) dominates at $V_{\mathrm{p}}>3700 \mathrm{~m} / \mathrm{s}$ and reservoir $\phi>22 \%$ in wells_2 and _3, while the shaly sands and shales/mudstones increase in the direction of moderate $V_{\mathrm{p}}<3250 \mathrm{~m} / \mathrm{s}$ and $\phi<20 \%$ (Fig. 7a, b). In wells _4, _5 and _9, the sandstones increase in the direction of moderate $V_{\mathrm{p}}<3250 \mathrm{~m} / \mathrm{s}$ and $\phi>22 \%$ and the shaly sands and shales/mudstones at $V_{\mathrm{p}}>3250 \mathrm{~m} / \mathrm{s}$ and $\phi<20 \%$ (Fig. 7c-e). These apparent variations in elastic wave velocities of the three lithofacies (sandstones, shaly sand and shales/mudstones) could be ascribed to varying degrees of compaction, clay content and diagenetic cementation of the reservoir matrix in the wells. Results suggest that the reservoir sandstones in wells_ 2 and
Table 1 Petrophysical properties of sand_5 reservoir interval

\begin{tabular}{llllllll}
\hline Well name & Top $(\mathrm{m})$ & Bottom $(\mathrm{m})$ & Thickness $(\mathrm{m})$ & Vsh $(\%)$ & N/G $(\%)$ & Porosity $(\%)$ & Sw $(\%)$ \\
\hline 2 & 1972 & 2025 & 53 & 10 & 90 & 25 & 14 \\
3 & 2109 & 2175 & 66 & 7 & 93 & 22 & 17 \\
4 & 2173 & 2207 & 34 & 18 & 82 & 24 & 19 \\
5 & 1857 & 1925 & 68 & 25 & 75 & 26 & 17 \\
9 & 1846 & 1932 & 86 & 22 & 78 & 25 & 16 \\
Average & - & - & 61.4 & 16.4 & 83.6 & 24.4 & 16.6 \\
\hline
\end{tabular}




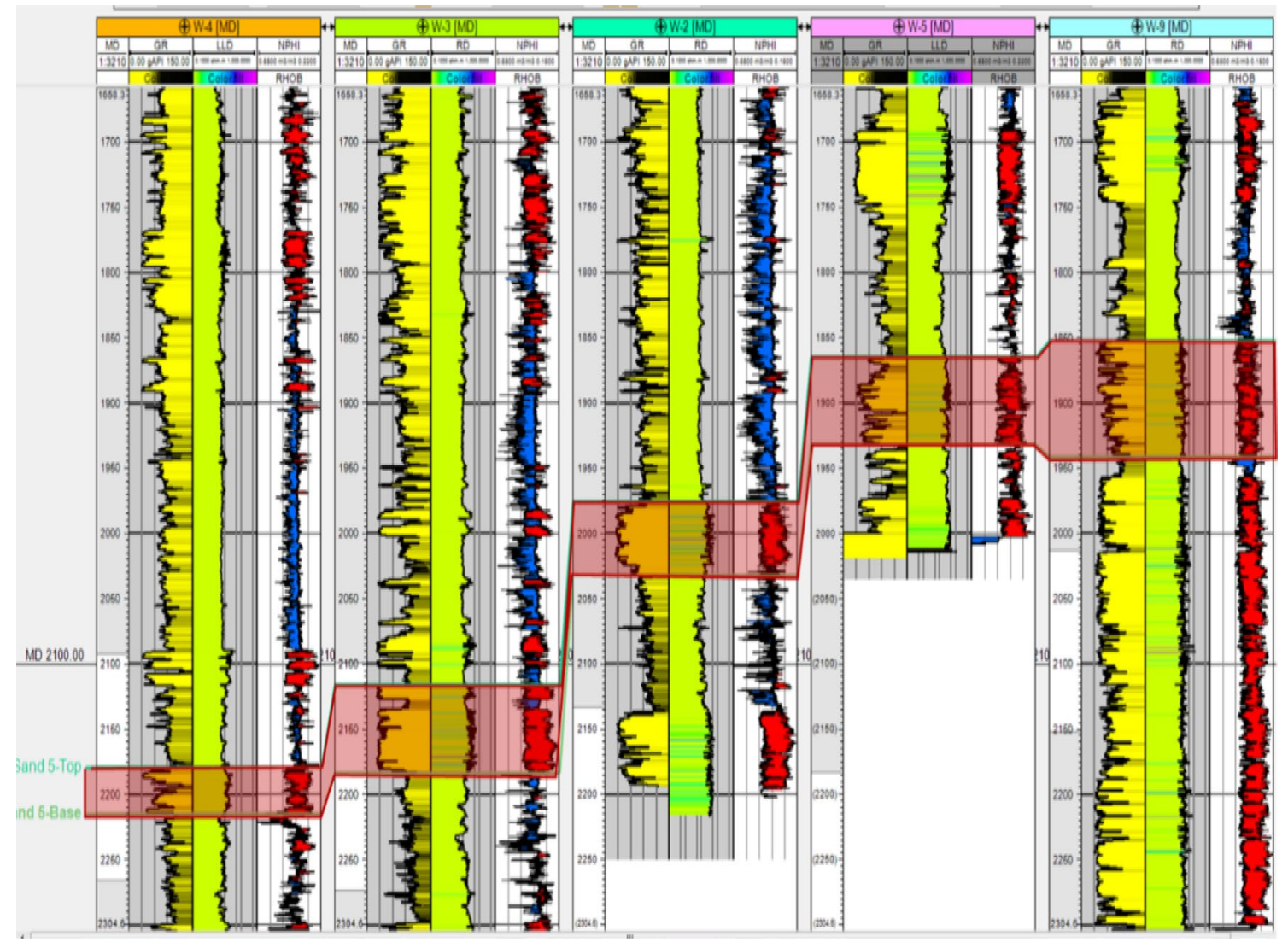

Fig. 6 Sand_5 reservoir interval correlated across wells

$\_3$ are more compacted than in wells_ $4, \ldots 5$ and _ 9 , but at comparable reservoir porosities. In the diagnostic plot for the all five wells (Fig. 7f), the data point's plots horizontally on the $V_{\mathrm{p}}-\phi$ plane are in line with the results of the individual crossplots in the respective wells/intervals validating the initial results. Result show that sand_5 reservoir interval is highly heterogeneous with respect to clay content and diagenetic cementation across the wells.

Results of the rock physics diagnostics revealed that of the three heuristic sand models evaluated (friable sand model, contact cement model and constant cement model), the constant cement sand model satisfactorily and quantitatively honors data points in wells_ 2, _3, _5 and _9 (Fig. 7a-e), while the friable sand model honors data points in well _4 (Fig. 7c). This suggests that reservoir sandstones are contact cemented with a constant cement volume throughout the rock in wells_ $2,33,5$ and $\_9$, and friable in well_ 4 .

To validate the result of the RPD and situate sand_5 reservoir interval to their appropriate depth points in the representative well_2, a crossplot of $\Phi N$ versus $\Phi D$ colorcoded with $V_{\text {sh }}$, depth and $V_{\mathrm{p}}$, respectively, was generated (Fig. 8a-c). The crossplot with $V_{\text {sh }}$ color code (Fig. 8a) distinguished clean and well-sorted sandstones (green ellipse) from shaly sands (red ellipse) and shales/mudstones (blue ellipse). Two distinct sandstone packs are recognizable from the crossplots with depth and $V_{\mathrm{p}}$ color codes, respectively, (Fig. 8b, c). These are the upper, low-velocity uncemented sands at subsurface depth $<1990 \mathrm{~m}$ (purple ellipse) and basal high-velocity cemented sandstones at subsurface depth $>2020 \mathrm{~m}$ (black ellipse). The shaly sands occur at subsurface depths $<1990 \mathrm{~m}$, while shales/mudstones occur partly at depths $<1990 \mathrm{~m}$ and $>2000 \mathrm{~m}$ (Fig. 8b, c).

The plot shows decreasing density porosity with increasing diagenetic cementation of the grain contacts at relatively low-neutron porosity for the consolidated and cemented sandstones with associated $V_{\mathrm{p}}>3250 \mathrm{~m} / \mathrm{s}$, whereas unconsolidated and friable sandstones show high-density porosity and corresponding low-neutron porosity with $V_{\mathrm{p}}<3250 \mathrm{~m} / \mathrm{s}$ within the reservoir interval. The shaly sands and shales/ mudstones exhibit decreasing density porosity but with increasing neutron porosity due to the increasing effect of clay mineralogy in the reservoir interval.

RPT plot of $V \mathrm{p} / V \mathrm{~s}$ versus $P$-Imp based on the constant cement model for representative well_2 sand_5 reservoir interval (Fig. 9) shows distinct lithology and pore fluid discriminations by the clustering of data points for a range of porosities (0-35\%) and saturations (0-100\%), with welldefined sand and shale lines. The sand line indicates the 

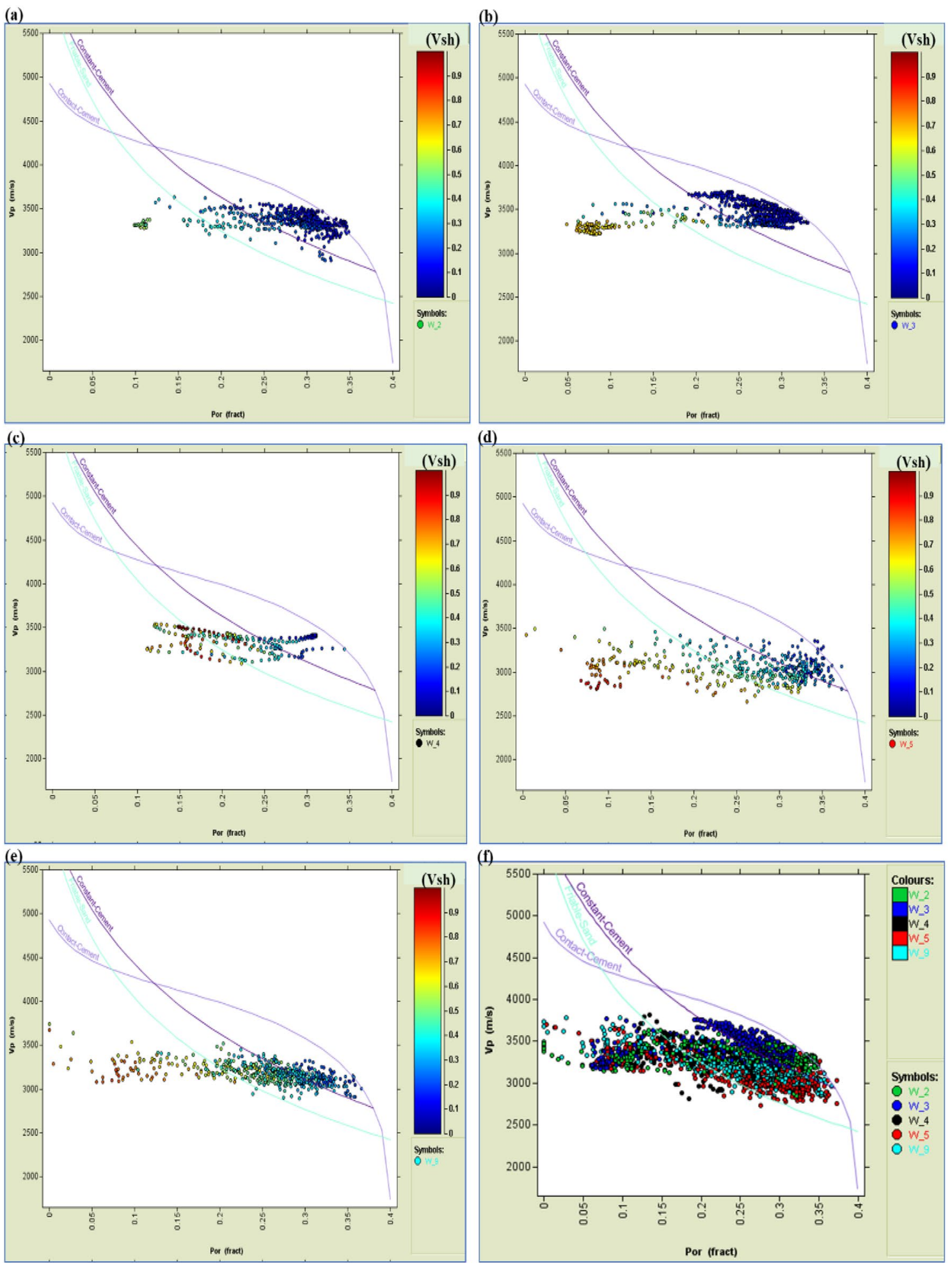

Fig. 7 Diagnostic plots of $V_{\mathrm{p}}$ versus $\phi$ (Por) for sand_5 with superimposed heuristic sands models in each well: a well-2; b well-3; c well-4; d well-5; $\mathbf{e}$ well-9; and $\mathbf{f}$ all five wells

formation compaction trend, and the direction orthogonal to this line is the fluid saturation trends parallel to each other at distinct porosities. Above the sand line is the shale line indicating shale compaction trend. Both lines are characterized by increasing compaction of the sediments for decreasing porosities. Porosity increases in the low impedance 

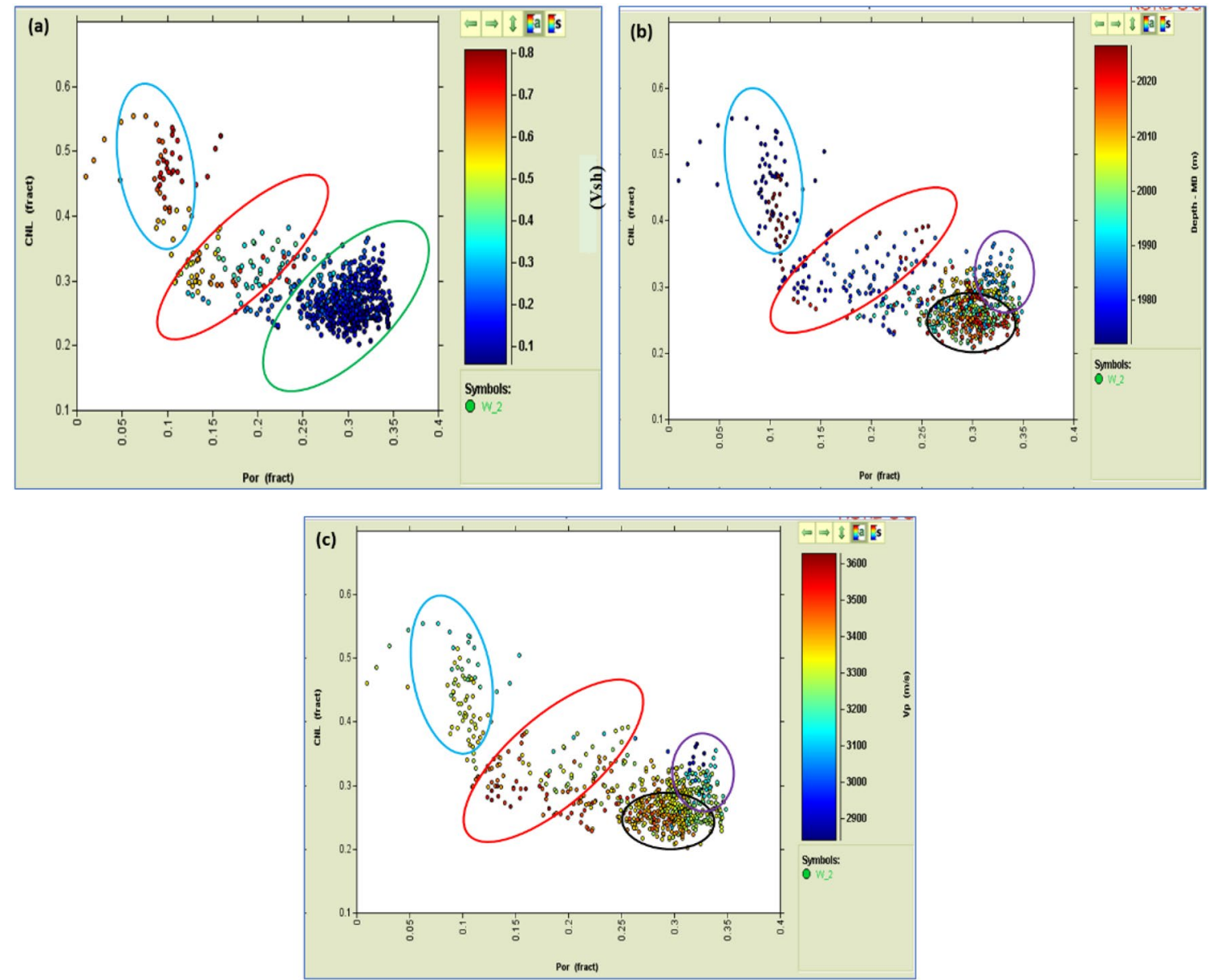

Fig. 8 Crossplots $\Phi N$ versus $\Phi D$ : a color-coded with $V_{\text {sh }}$, b color-coded with depth, c color-coded with $V_{\mathrm{p}}$

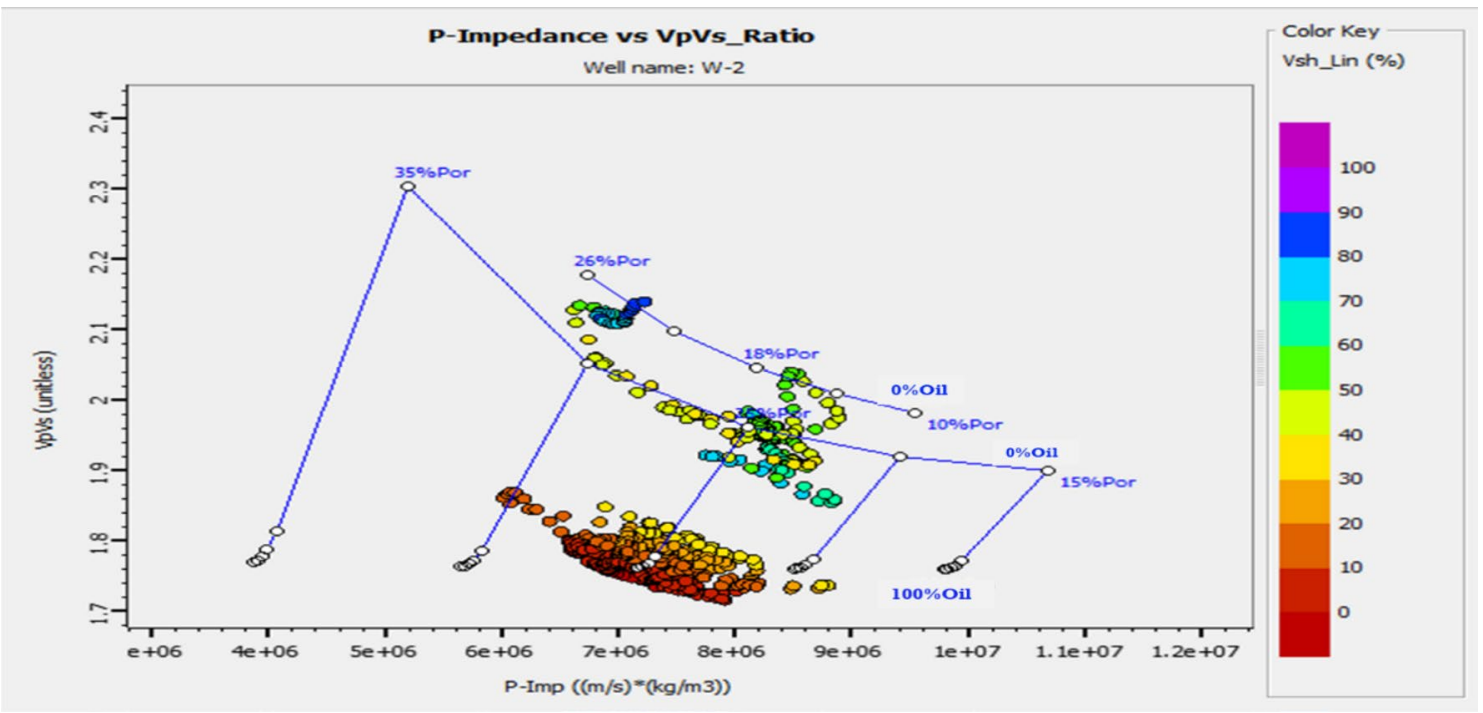

Fig. 9 RPT for well_2 sand_5 reservoir interval 
direction, while hydrocarbon saturation increases in the low $V_{\mathrm{p}} / V_{\mathrm{s}}$ direction, and clay content (shaleness) increases in the high $V_{\mathrm{p}} / V_{\mathrm{s}}$ direction. Result shows hydrocarbon sandstones were diagnosed with medium-to-high impedance and low $V_{\mathrm{p}} / V_{\mathrm{s}}$ ratio, with average hydrocarbon saturation and porosity values of $82.5 \%$ and $24.5 \%$, respectively. Brine shaly sands were diagnosed with medium-to-high impedance with moderate $V_{\mathrm{p}} / V_{\mathrm{s}}$ and the shales/mudstones with medium impedance and high $V_{\mathrm{p}} / V_{\mathrm{s}}$.

\section{Discussion of results}

Reservoir rocks (sandstones, shaly sands and shales/mudstones) and pore fluids were discriminated and characterized by poor property contrast in the log responses. Petrophysical analysis delineated and mapped Sand_5 reservoir interval by moderate GR and low-resistivity log signatures, whereas shales/mudstones were mapped by moderately high GR and low-resistivity log signatures. These characteristic log responses are attributed to high clay and radioactive mineral content in the rocks; typical of most wells in the Termit subbasin are obvious characteristics of LCLR reservoirs (Zhiqiang et al. 2007; Chang and Zung 2017). Further petrophysical evaluation revealed that Sand_5 interval exhibits fairly good reservoir properties (thickness, porosity, volume of shale, water saturation and hydrocarbon saturation values of $61.0 \mathrm{~m}, 24.4 \%, 16.4 \%, 16.6 \%$ and $83.4 \%$, respectively) and continuous across the five wells but with varying thicknesses and depths.

Reservoir characterization of LCLR sand_5 interval using only conventional petrophysical method could give failed results due to poor property contrasts at the well scale. Therefore, rock physics approach was adopted to evaluate Eocene sandstone reservoir microstructure and quality for robust quantitative reservoir evaluation in the subbasin. Rock physics diagnostic plot of $V p$ versus $\phi$ for sand_5 reservoir interval produced distinct data trends that tend to be fairly horizontal suggesting grain size distribution of different lithologies related to the environment of deposition and burial history (Avseth et al. 2010). From the crossplots, reservoir sandstones increase in the direction of increasing $V_{\mathrm{p}}$ at fairly high reservoir $\phi$ in wells_2 and_3, while the shaly sands and shale increase in the direction of moderate $V_{\mathrm{p}}$ and $\phi$. In wells_4, 5 _ and_9, the sandstones increase in the direction of moderate $\mathrm{V}_{\mathrm{p}}$ and high reservoir $\phi$ and the shaly sands and shales at moderate $V_{\mathrm{p}}$ and low $\phi$.

These results suggest a cleaner and more consolidated reservoir sandstone interval in wells_2 and _ 3 than in wells_4, _5 and _9. These variations could be attributed to differences in the environment of deposition, burial depths and diagenetic alterations across wells resulting to increased matrix stiffness at reduced porosity and high elastic wave velocities in wells _2 and _3 than the low velocity sands in wells_4,_5 and_9 (Avseth et al. 2000,2010; Chopra and Marfurt 2006; Lai et. al. 2020). RPD analysis revealed that of the three heuristic sand models evaluated (friable sand, constant cement and contact cement sand models), the constant cement sand model quantitatively described reservoir microstructure in wells_2, $33, \ldots 5$ and _ 9 , and the friable sand model in well_4. These results suggest that reservoir sandstones in wells_2, 33 _5 and _9 are consolidated and contact-cemented, while in well_4 reservoir sandstones are unconsolidated and uncemented.

These results were subsequently validated for representative well_2 sand_5 interval by crossplotting $\Phi N$ versus $\Phi D$ color-coded with $V_{\text {sh }}$, depth and $V \mathrm{p}$, respectively. Result shows distinct sandstone packs, namely the upper low-velocity unconsolidated sandstones at subsurface depth $<1990 \mathrm{~m}$ and basal high-velocity consolidated and cemented sandstones at subsurface depth $>2020 \mathrm{~m}$. The upper unconsolidated and friable sandstones exhibit high-density porosity and low-neutron porosity with $V p<3250 \mathrm{~m} / \mathrm{s}$, whereas the basal consolidated and cemented sandstones exhibit decreasing density porosity due to increasing diagenetic cementation of the grain contacts at relatively low-neutron porosity with associated $V p>3250 \mathrm{~m} / \mathrm{s}$. The low-neutron porosity of both sands in the reservoir is an indication of clean and wellsorted sandstones with insignificant clay content. The shaly sands occur at subsurface depths $<1990 \mathrm{~m}$, while shales/ mudstones occur partly at depths $<1990 \mathrm{~m}$ and $>2000 \mathrm{~m}$. The shaly sands and shales/mudstones exhibit decreasing density porosity but with increasing neutron porosity attributed to increasing clay content in the matrixes.

The reservoir matrix varies between very clean and well-sorted unconsolidated sands as well as consolidated and cemented sandstones of high-energy depositional environment to deteriorating and poorly sorted shaly sands and shales/mudstones of low-energy depositional environment (Avseth et al. 2010, 2014; Chang and Zung 2017). These observations suggest that sand_5 reservoir interval is composed of sediments from many sedimentary cycles in which both well to poorly sorted sandstones were deposited into interchanging energy depositional environments and burial history. The present analysis shows that the reservoir interval is highly heterogeneous with respect to clay content and diagenetic cementation across the wells, resulting to property variations and possible compartmentalization of the reservoir across wells.

RPT plot of $V_{\mathrm{p}} / V_{\mathrm{s}}$ versus P-Imp for the representative well_2 and sand_5 interval built from the constant cement sand model shows distinct lithology and pore fluid discriminations by the clustering of data points for a range of porosity and water saturation values. Hydrocarbon reservoir sandstones were diagnosed with a characteristic mediumto-high impedances and low $V_{\mathrm{p}} / V_{\mathrm{s}}$ ratio. Brine shaly sands

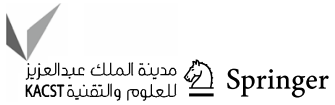


and shales/mudstones were diagnosed with medium-to-high impedances and moderate $V_{\mathrm{p}} / V_{\mathrm{s}}$ ratio and medium impedance and high $V_{\mathrm{p}} / V_{\mathrm{s}}$ ratio, respectively. These results reveal that hydrocarbon sandstones and brine shaly sandstones cannot be discriminated completely on the basis of the impedance property as do the shales/mudstones since they exhibit similar impedance characteristics. However, hydrocarbon sandstones, brine shaly sands and shale/mudstones are completely discriminated by characteristic $V_{\mathrm{p}} / V_{\mathrm{s}}$ property in the subbasin.

These revelations are especially important in the Termit subbasin where most of the reservoirs are less than one quarter of a wavelength thick with associated complexities in structure and poor matrix property contrasts. Based on RPT analysis, average hydrocarbon saturation and reservoir porosity are predicted to be $82.5 \%$ and $24.5 \%$, respectively, which correlates with the $83.4 \%$ and $24.4 \%$ hydrocarbon saturation and porosity values, respectively, from well-based petrophysical measurements, validating the adequacy of the models.

\section{Conclusion}

Petrophysics and rock physics diagnostic modeling have been adopted in an integrated scheme to evaluate reservoir microstructure and quality for quantitative reservoir characterization in Termit subbasin. Sand_5 reservoir interval exhibits good reservoir characteristics and prolific in hydrocarbons, especially oil. RPD analysis revealed that sand_5 reservoir interval can be best described by the constant cement sand model in wells_2, _3, _5 and _9 and friable sand models in well_4. The matrix structure varied mostly from clean and well-sorted unconsolidated sands as well as consolidated and cemented sandstones of high-energy depositional environment to deteriorating and poorly sorted shaly sands and shales/mudstones of low-energy depositional environment. Through RPT analysis based on the constant cement model, the representative well_2 and sand_5 reservoir interval was diagnosed with a medium-to-high impedance and low $V \mathrm{p} / V \mathrm{~s}$ attributes characteristic of hydrocarbon saturation. Brine shaly sands and shales/mudstones were diagnosed with medium-to-high impedance and moderate $V \mathrm{p} / V_{\mathrm{s}}$ and medium impedance and high $V \mathrm{p} / V_{\mathrm{s}}$, respectively.

On the basis of these results, it is obvious that hydrocarbon sandstones and brine shaly sandstones cannot be distinctively discriminated from the impedance property since they exhibit similar impedance characteristics. However, hydrocarbon sandstones, brine shaly sands and shale/ mudstones are completely discriminated by their characteristic $V_{\mathrm{p}} / V_{\mathrm{s}}$ property in the subbasin. These results demonstrate the robust application of RPD in evaluating reservoir microstructure and quality for quantitative reservoir characterization in Termit subbasin.

Acknowledgements We would like to thank the Ministry of Petroleum, Niger Republic, for providing the data for this study, and for permission to publish this work. Our thanks also go to World Bank African Centre of Excellence, Centre for OilField Chemical Research (ACE-CEFOR), University of Port Harcourt, for giving the opportunity to conduct this research and by the way providing a frame to develop human capital for the petroleum industry to enhance real sustainable progress in oil and gas industry in Africa.

Funding None.

\section{Declarations}

Conflict of interest On behalf of all the co-authors, the corresponding author states that there is no conflict of interest.

Open Access This article is licensed under a Creative Commons Attribution 4.0 International License, which permits use, sharing, adaptation, distribution and reproduction in any medium or format, as long as you give appropriate credit to the original author(s) and the source, provide a link to the Creative Commons licence, and indicate if changes were made. The images or other third party material in this article are included in the article's Creative Commons licence, unless indicated otherwise in a credit line to the material. If material is not included in the article's Creative Commons licence and your intended use is not permitted by statutory regulation or exceeds the permitted use, you will need to obtain permission directly from the copyright holder. To view a copy of this licence, visit http://creativecommons.org/licenses/by/4.0/.

\section{References}

Ahmad MN, Rowell P (2013) Rock physics analysis: a tool for lithology and fluid prediction in the Gulf of Thailand. ASEG-PESA 2013, The EUREKA MOMENT. In: 23rd International geophysical conference and exhibition, Melbourne, Australia

Avseth P, Dvorkin J, Mavko G, Rykkje J (2000) Rock physics diagnostic of North Sea Sands: link between microstructure and seismic properties. Geophys Res Lett 27:2761-2764. https:// doi.org/10.1029/1999GL008468

Avseth P, Mukerji T, Mavko G (2005) Quantitative seismic interpretation: applying rock physics tools to reduce interpretation risk. Cambridge University Press

Avseth P, Mukerji T, Mavko G, Dvorkin J (2010) Rock physics diagnostics of depositional texture, diagenetic alterations, and reservoir heterogeneity in highporosity siliciclastic sediments and rocks: a review of selected models and suggested workflows. Geophysics 75(5):A31-A47. https://doi.org/10.1190/1.3483770

Avseth P, Johansen TA, Bakhorji A, Mustafa HM (2014) Rock-physics modelling guided by depositional and burial history in lowto-intermediate-porosity sandstones. Geophysics 79(2):D115D121. https://doi.org/10.1190/geo2013-0226.1

Bjørlykke K (2010) Petroleum geoscience: from sedimentary environments to rock physics. Springer, Berlin, p 518p

Bosch M, Mukerji T, Gonzalez EF (2017) Seismic, rock physics, spatial models, and their integration in reservoir geophysics. SEG Encyclop Explor Geophys. https://doi.org/10.1190/1. 9781560803027 
Chang E, Zung LS (2017) 3D reservoir characterization of field deta, Termit Basin, Niger. Springer, Berlin, pp 323-335. https://doi. org/10.1007/978-981-10-3650-7_28

Chopra S, Marfurt K (2006) Seismic attributes: a promising aid for geologic prediction. CSEG Recorder 31(Special):10-121

Colin MS, Lennert DDB (2011) Rock physics-based relations for density and S-velocity versus P-velocity in deepwater subsalt Gulf of Mexico shales. Lead Edge 30:1376-1381

Dvorkin J, Nur A (1996) Elasticity of high-porosity sandstones: theory for two north sea data sets. Geophysics 61:1363-1370. https://doi. org/10.1190/1.1444059

Dvorkin J, Gutiérrez MA, Nur A (2002) On the universality of diagenetic trends. Lead Edge 21(1):40-43. https://doi.org/10.1190/1. 1445846

Dvorkin J, Nur A, Yin H (1994) Effective properties of cemented granular material. Mech Mater 18:351-366. https://doi.org/10.1016/ 0167-6636(94)90044-2

Gassmann F (1951) Über Die Elastizität Poröser Medien: Vierteljahrsschrift der Naturforschenden Gesellschaft in Zürich 96:1-23

Genik GJ (1993) Petroleum geology of cretaceous-tertiary rifts Basins in Niger, Chad and Central African Republic. Am Asso Petrol Geol Bull 73(8):153-168

Genik GJ (1992) Regional framework, structural and petroleum aspects of rift basins in Niger, Chad and the Central African Republic (C.A.R.), vol 213. Elsevier Science Publishers B.V., Tectonophysics, pp 169-185. https://doi.org/10.1016/0040-1951(92)90257-7

Greenberg ML, Castagna JP (1992) Shear-wave estimation in porous rocks: theoretical formulation, preliminary verification and applications. Geophys Prospect 40(2):195-209. https://doi.org/10. 1111/j.1365-2478.1992.tb00371.x

Harouna M, Philp RP (2012) Potential petroleum source rocks in the Termit Basin, Niger. J Pet Geol 35(2):165-186. https://doi.org/10. 1111/j.1747-5457.2012.00524.x

Hassane A, Ehirim CN, Dagogo T (2021) Well-based quantitative reservoir characterization of eocene sokor-1 formation, Termit Basin, Niger. Int J Geosci 12(2):159-169

Kabanda A (2017) Rock physics template (RTP) technology for reservoir characterization and 4D seismic monitoring. CSEG Recoder 42(1):30-33

Lai H, Li M, Mao F, Liu J, Xiao H, Tang Y, Shi S (2020) Source rock types, distribution and their hydrocarbon generative potential within the Paleogene Sokor- 1 and LV formations in Termit Basin. Niger Energy Explor Exploit 38(6):1-26. https://doi.org/ 10.1177/0144598720915534
Liu B, Wan L, Mao F, Liu J, Lü M, Wang Y (2015) Hydrocarbon potential of Upper Cretaceous marine source rocks in the Termit Basin, Niger. J Pet Geol 38(2):157-175. https://doi.org/10.1111/ jpg. 12604

Liu J, Zhang G, Li Z, Tang Y, Xiao H, Lai H, Yang C (2019) Oil charge history of paleogene-eocene reservoir in the termit Basin (Niger). Aust J Earth Sci 66(4):597-606. https://doi.org/10.1080/08120 099.2019 .1568301

Liu B, Pan X, Wan L, Mao F, Liu JLM, Wang Y, Jiang H (2012) Polyphase rift evolution of the Termit Basin, eastern Niger: Constraints from structural and sedimentary records. Geoscience 26:317-325. https://doi.org/10.3969/j.issn.10008527.2012.02.012

Mahbaz S, Sardar H, Memarian H (2012) Determination of a rock physics model for the carbonate Fahliyan Formation in two oil wells in southwestern Iran. Explor Geophys 43:47-57. https:// doi.org/10.1071/EG11006

Mavko G, Mukerji T, Dvorkin J (2009) The rock physics handbook. Cambridge University Press

Ødegaard E, Avseth P (2004) Well log and seismic data analysis using rock physics templates. First Break 22(10):37-43

Simm R, Bacon M (2014) seismicamplitude: an interpreter's handbook. Cambridge Press, p 282

Wan L, Liu J, Mao FLM, Liu B (2014) The petroleum geochemistry of the Termit Basin, Eastern Niger. Mar Pet Geol 51:167-183. https://doi.org/10.1016/j.marpetgeo.2013.11.006

Warren MJ (2009) Tectonic inversion and petroleum system implications in the rifts of Central Africa. Jenner GeoConsulting, Suite 2008, 1235 17th Ave SW, Calgary, Alberta, Canada, T2T 0C2. Frontiers+Innovation, CSPG SCEG CWLS Convention, pp 4-8

Wyllie MRJ, Gregory AR, Gardner GH (1956) Elastic wave velocities in heterogeneous and porous media. Geophysics 21:41-70

Zhiqiang M, Lichun K, Chengwen X, Guoxin L, Cancan Z, Jian O (2007) Identification and evaluation of low resistivity pay zone by Well Logs and the petrophysical research in China. Pet Sci 4(1):41

Zhou L, Su J, Dong X, Shi B, Sun Z, Qian M, Lou D, Liu A (2017) Controlling factors of hydrocarbon accumulation in termit rift superimposed basin. Niger Pet Explor Dev 44(3):358-367

Publisher's Note Springer Nature remains neutral with regard to jurisdictional claims in published maps and institutional affiliations. 